\title{
Synthesis of biodiesel from vegetable oils wastewater sludge by in-situ subcritical methanol transesterification: Process evaluation and optimization
}

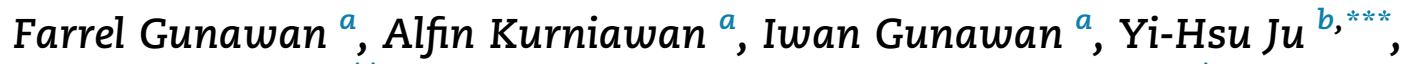 \\ Aning Ayucitra ${ }^{a, * *}$, Felycia E. Soetaredjo ${ }^{a}$, Suryadi Ismadji ${ }^{a, *}$ \\ ${ }^{a}$ Department of Chemical Engineering, Widya Mandala Surabaya Catholic University, Kalijudan 37, Surabaya \\ 60114, Indonesia \\ ${ }^{\mathrm{b}}$ Department of Chemical Engineering, National Taiwan University of Science and Technology, No. 43, Sec. 4, \\ Keelung Rd., Taipei 106-07, Taiwan, ROC
}

\section{A R T I C L E I N F O}

Article history:

Received 7 May 2013

Received in revised form

3 July 2014

Accepted 5 July 2014

Available online 24 July 2014

Keywords:

Wastewater sludge

Subcritical methanol

In-situ transesterification

Biodiesel

Statistical design

\begin{abstract}
A B S T R A C T
Biodiesel are gaining increased public and scientific attention as an alternative to petroleum diesel fuel, driven by factors such as oil price spikes, energy security and environmental concerns. In this study, low grade wastewater sludge originated from wastewater treatment unit of vegetable oil factory as a viable alternative lipid source for biodiesel production was evaluated. The lipid mass fraction of the dry and ash-free sludge was $12.44 \pm 0.87 \%$, which mainly comprised of C16-C18 fatty acids. The in-situ transesterification process under subcritical water and methanol conditions was applied as a green pathway to convert lipids into fatty acid methyl esters (FAMEs). The reaction parameters investigated were temperatures $\left(155-215{ }^{\circ} \mathrm{C}\right)$, pressures $(5.5-6.5 \mathrm{MPa})$ and methanol to lipid mass ratios (1:1, 5:1 and 9:1). The highest FAME yield of $92.67 \pm 3.23 \%$ was obtained at $215{ }^{\circ} \mathrm{C}, 6.5 \mathrm{MPa}$ and methanol to lipid mass ratio of 5:1. Statistical analysis based on response surface methodology in 3-factor-3-level central composite designed experiments and analysis of variance were applied to examine the relation between input parameters and the response and to locate the optimum condition. Results showed that $98 \%$ of the variability in the response could be adequately explained by the second-order polynomial model. The optimum FAME yield (90.37\%) was obtained at $215{ }^{\circ} \mathrm{C}, 6.5 \mathrm{MPa}$ and methanol to lipid mass ratio of 5.12:1. Experimental validation $(N=3)$ demonstrated satisfactory agreement between the observed and predicted values with an error of at most $3.3 \%$.
\end{abstract}

() 2014 Elsevier Ltd. All rights reserved.

\footnotetext{
* Corresponding author. Tel.: +62 31389 1264; fax: +62 313891267.

** Corresponding author.

*** Corresponding author. Tel.: +886 22737 6612; fax: +886 227376644.

E-mail addresses: alfin_kur@yahoo.com (A. Kurniawan), yhju@mail.ntust.edu.tw (Y.-H. Ju), aayucitra@yahoo.com (A. Ayucitra), suryadiismadji@yahoo.com (S. Ismadji). 


\section{Introduction}

The development of sustainable biofuels is vitally crucial to global transportation and many industrial operations to generate electricity and heat. Such today's concern is driven by long-term supply issue associated with fossil fuels and their environmental impacts due to the release of carbon dioxide, $\mathrm{SO}_{\mathrm{x}}$ and $\mathrm{NO}_{\mathrm{x}}$ pollutants during fuel combustion. One of potential alternative and sustainable biofuels which have been extensively studied and now commercially produced is biodiesel. Although biodiesel produces less air pollutants and is fast becoming a currently recognized substitute and/or blending agent for petroleum diesel, yet it still possesses key limitations include a heavy price, life-cycle assessment and the necessity of a vast land to produce enough biofuel without threatening food supplies and biodiversity.

There are a number of factors affecting high variable costs in the production of biodiesel, limiting the fuel's widespread use. In this light, the cost of biodiesel feedstock is the most burdensome, which accounts for $70-85 \%$ of total cost of production [1]. Palm oil [2], soybean oil [3], corn oil [4], rapeseed oil [5], sunflower oil [6], sesame oil [7], rice bran oil [8] and a number of other food crops have all served as feedstock for biodiesel, however they all suffer from the same problems including threatening the food chain, increasing carbon emissions when planted outside traditional agricultural settings and intense growth requirements. Animal fats such as beef tallow [9], poultry fat [10], fish oil [11] and pork lard [12] have been investigated to produce biodiesel. Although much of animal fats are not considered edible by humans and their cost is substantially lower than the cost of vegetable oils, yet their applications can be challenging because they frequently contain contaminants (e.g., phospholipids and gums) that should be removed before the fuel is used in an engine and also animal fat-based biodiesel typically has higher viscosity and sulfur content. Therefore, it is necessary to gain a new perspective on the production of biodiesel by seeking an alternative feedstock, which is non-food crops and easily obtainable in large quantities. Recently, municipal wastewater sludge is being explored for its untapped potential as a cheap and readily available lipid feedstock for sustainable biodiesel production. The sewage sludge is a by-product generated after wastewater treatment and usually a blend of thickened primary and secondary sludges. This sludge contains considerable mass fraction of lipids (up to 30\%) either as a composite organic matrix (oils, greases, sterols, fats and long-chain fatty acids) originated from direct adsorption of lipids in municipal and industrial wastewater or from phospholipids in the cell membrane of microorganisms, their metabolites and by-products of cell lysis [13]. The conventional technology to produce biodiesel from sewage sludge is by a two-step process involving lipid extraction using organic solvents and then alcoholysis of extracted lipids. However, this usual approach poses a great challenge for industrial practice. The lipid recovery process from sewage sludge is tedious and costly because it requires huge amounts of organic solvents and large vessels with stirring and heating systems. Also, most of organic solvents used for extracting lipids are not environmentally acceptable. In addition, the alcoholysis either by esterification or transesterification using liquid or solid catalysts often creates limitations in the catalyst recovery, yield and purity of biodiesel and treatment of wastewater. Kwon et al. [14] had demonstrated a thermochemical approach to transform lipids to biodiesel employing a catalyst-free, continuous flow system. However, noncatalytic thermochemical process suffers from the drawback of intense energy consumption due to the use of high temperatures $\left(350-500{ }^{\circ} \mathrm{C}\right.$ ) although nearly complete conversion reaction is achieved within a short period of time.

Subcritical water (SubCW), that is, pressurized water at temperatures above the boiling point at ambient pressure and below critical point $\left(\mathrm{T}_{\mathrm{C}}=374{ }^{\circ} \mathrm{C}\right)$, is considered as a unique and green reaction medium for various applications including catalytic/non-catalytic reactions, biomass transformation to chemicals and materials and extraction of bioactive compounds from natural matrices. Several relevant properties of SubCW as a reaction medium are miscibility, ionic product, electrolytic solvent power, dielectric constant and transport properties (e.g., viscosity, diffusivity and ion mobility). The physicochemical properties of interest of SubCW can be tuned through changes in pressure and temperature. With the increase of temperature, there is a marked and systematic decrease in permittivity, viscosity and surface tension while the diffusion rate increases [15]. In the extraction of lipids by SubCW, the process is feasible at mild temperatures (typically $150-200{ }^{\circ} \mathrm{C}$ ) due to reduced dielectric constant of water, making it capable to extract weakly polar to non-polar compounds. A successful implementation of SubCW as a green alternative solvent to recover lipids from wet algae [16] and dewatered activated sludge [17] has been reported and the possibility of producing biodiesel from wet activated sludge without any catalyst under subcritical water and methanol condition has been investigated by Huynh et al. [18]. In their recent paper, dried activated sludge was used instead of wet activated sludge as the lipid feedstock and water was added prior to methanolysis. Drying of wet activated sludge is a time-consuming as well labor- and energy-intensive process and for large-scale operation, this process is not economically feasible due to large fuel consumption in drying machine or huge land area for sun drying process.

To date, limited studies on the production of biodiesel from wet activated sludge can be found in literature. In most cases, transesterification is performed under catalytic action of acidic or base homogeneous/heterogeneous catalysts, either in single or two-step processes. In contrast to such method, the in-situ transesterification procedure under subcritical alcohol condition is an ongoing area of intense research. Therefore, the aims of this study are to evaluate in-situ transesterification of wet wastewater sludge to fatty esters under subcritical water and methanol conditions along with the influencing parameters (temperature, pressure and methanol to lipid mass ratio) and to determine the optimum reaction condition by employing response surface methodological approach (RSM) and analysis of variance (ANOVA). Several key properties of biodiesel is also investigated and compared to ASTM D6751 standard. 


\section{Materials and methods}

\subsection{Materials}

Fresh wastewater sludge was collected from a vegetable oil wastewater treatment unit located at Surabaya city, East Java. Distilled water was obtained from a local supplier. Anhydrous methanol (99.8\%) and $n$-hexane (95\%) was supplied from Merck, Germany while ultra pure $\mathrm{N}_{2}$ gas $(99.9 \%)$ was supplied from a local company. The fatty acid methyl esters (FAMEs) reference standard mix (Supelco) consisting of C14-C22 fatty acids was purchased from Sigma Aldrich Co., Singapore and used without any further purification.

\subsection{In-situ subcritical methanol transesterification}

The experimental setup of a lab-scale high pressure batch reactor in this work $\left(150 \mathrm{~cm}^{3}\right.$, temperature limit: $273-473 \mathrm{~K}$, pressure range: $0-10 \mathrm{MPa}$ ) is shown in Fig. 1. The reactor was made of Type 316 stainless steel and equipped with an external heater, a pressure gauge, a Type $\mathrm{K}$ thermocouple and M8 screws for tightening the reactor with its cap. The reaction vessel was charged with a given quantity of wet sludge and methanol (methanol to sludge mass ratios of 1:1, 5:1 and 9:1). Here, mass ratio was used instead of molar ratio to represent methanol loading due to the difficulty in calculating exact molecular weight of the sludge containing numerous components. $\mathrm{N}_{2}$ was then flowed into the reactor to remove air and build a bit of pressure prior to heating. The reactor was heated at $20 \mathrm{~K} \mathrm{~min}^{-1}$ from room to desired temperatures $\left(155-215{ }^{\circ} \mathrm{C}\right)$ and kept at final temperatures for $12 \mathrm{~h}$. To maintain an isothermal and isobaric condition, temperature was controlled by a PID-type controller with uncertainty of $\pm 1{ }^{\circ} \mathrm{C}$ and pressure was monitored in real time by a pressure gauge. During the reaction period, the mixture was magnetically stirred at a constant rate of $13.33 \mathrm{~Hz}$. When final temperature was reached, the pressure inside the reaction vessel ranged between 5.5 and $6.5 \mathrm{MPa}$.

After completion of the reaction, the reactor was immersed in a cold water bath for immediate cooling and the vapor

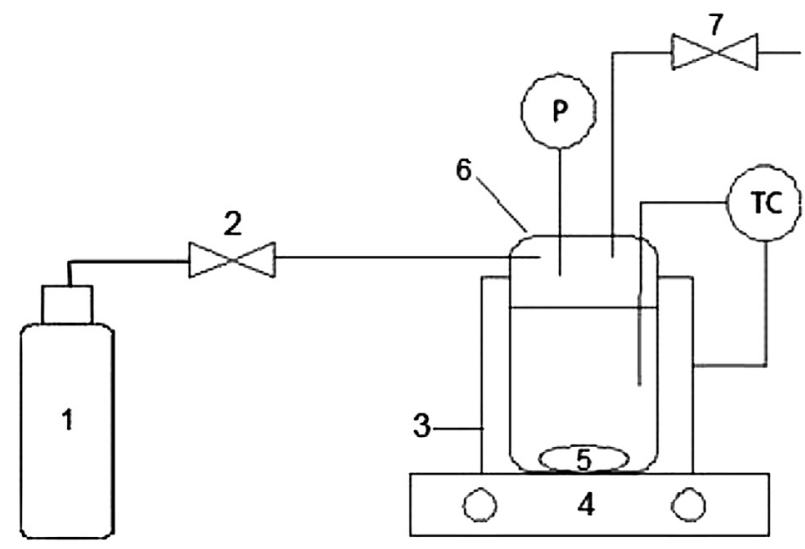

Fig. 1 - Schematic diagram of the subcritical reactor system: $\mathrm{N}_{2}$ cylinder (1); relief valve (2); electric heating element (3); RPM controller (4); magnetic bar (5); highpressure reactor (6); release valve (7). mixture was vented to the condenser inlet. The condensate was collected in a conical flask and extracted with $n$-hexane. The liquid contents were placed in the separatory funnel and after addition of $n$-hexane and shaking; the mixture was allowed to settle for $24 \mathrm{~h}$ to ensure complete separation between ester-rich (organic) and glycerol-rich (aqueous) phases. The aqueous phase (bottom phase) was removed and left in a separate container. The organic phase was evaporated in vacuum to remove $n$-hexane. The solid fraction was removed and a given amount of $n$-hexane was added to extract fatty esters and unreacted lipids. The extraction process was conducted in a stirred borosilicate cylindrical glass vessel for $2 \mathrm{~h}$ with a constant stirring rate of $13.33 \mathrm{~Hz}$. The solid was removed using a Buchner filtering funnel. The retained solid was washed three times with $50 \mathrm{~cm}^{3} n$-hexane. The removal of $n$-hexane was conducted in vacuum using a rotary evaporator flask and the mass of biodiesel (FAMEs) was weighed using an analytical balance (Mettler Toledo).

\subsection{Analysis of FAME mass fraction}

The FAME mass fraction was assayed by gas chromatography, in a Shimadzu GC 2014 equipped with a flame ionization detector (FID) and an Agilent DB-WAX capillary column $(30 \mathrm{~m}$ length, $0.25 \mathrm{~mm}$ i.d., $0.25 \mu \mathrm{m}$ film thickness). Highly pure helium $(99.9 \%)$ was used as the carrier gas at a linear velocity of $40 \mathrm{~cm} \mathrm{~s}^{-1}$. The injector temperature was set at $250^{\circ} \mathrm{C}$ running in splitless mode and the detector temperature was kept at $300{ }^{\circ} \mathrm{C}$ for the duration of analysis. The oven temperature program was started at $50{ }^{\circ} \mathrm{C}$ with a holding time of $2 \mathrm{~min}$, then ramped to $250{ }^{\circ} \mathrm{C}$ at $10 \mathrm{~K} \mathrm{~min}^{-1}$ and held constant at $250{ }^{\circ} \mathrm{C}$ for $8 \mathrm{~min}$. The injection volume of the samples was $1 \mathrm{~mm}^{3}$. Calibration of the instrument was conducted using a 10-component FAMEs standard mix with methyl heptadecanoate as internal standard. All calibration curves were linear with a correlation coefficient of 0.98 or better. Peaks of FAMEs were identified by comparing retention time with those of FAMEs standard mix. FAMEs not included in this standard were compared with the peaks of well-recognized materials under similar analytical conditions. The FAME mass fraction was determined by the following equation:

$F_{\mathrm{C}}(\%)=100\left(\frac{\sum A_{\text {FAME }}-A_{\text {int }}}{A_{\text {int }}} \times \frac{V_{\text {int }} C_{\text {int }}}{m}\right)$

where $F_{\mathrm{C}}$ is the FAME mass fraction, $\sum A_{\mathrm{FAME}}$ is total peak area of FAMEs, $A_{\text {int }}$ is the peak area of methyl heptadecanoate, $V_{\text {int }}$ is the volume of methyl heptadecanoate internal standard solution added to sample $\left(\mathrm{cm}^{3}\right), C_{\text {int }}$ is the concentration of methyl heptadecanoate internal standard solution $\left(\mathrm{g} \mathrm{cm}^{-3}\right)$ and $m$ is the mass of sample (g). The percent yields of FAMEs based on lipid mass fraction of the dry and ash-free sludge were calculated as follows:

Yield $(\%)=\frac{100 \times m_{\mathrm{p}} \times F_{\mathrm{c}}}{m_{\mathrm{l}}}$

where $m_{p}$ is the mass of biodiesel $(g), m_{l}$ is the mass of lipids in the dry and ash-free sludge $(\mathrm{g})$ and $F_{\mathrm{c}}$ is the FAME mass fraction obtained from Eq. (1).

Thin-layer chromatography (TLC) was carried out for qualitative analysis of fatty esters, employing silica gel TLC 
plates (Polygram ${ }^{\circledR}$ Sil G) on polyester support $(20 \mathrm{~cm} \times 20 \mathrm{~cm}$, $0.20 \mathrm{~mm}$ ). The product was dissolved in $n$-hexane and spotted on a TLC plate which was then developed using a solvent mixture of $n$-hexane, ethyl acetate and acetic acid (volume ratios of 90:10:1) in a covered glass vessel until the solvent front reached the top of the plate. After a brief drying, the plate was dipped in a water bath for 1-2 min. The wet plate was stained in $100 \mathrm{~cm}^{3}$ of $1 \% \mathrm{KMnO}_{4}$ solution in $4 \% \mathrm{NaOH}$ for approximately $20 \mathrm{~s}$ with constant agitation for visualization [19]. Then, the stained plate was extensively washed with water (3-4 changes for 3-4 min) and dried. The individual fractions as spots on the plate were identified by comparing $R_{f}$ values with authentic standards of known masses.

\subsection{Biodiesel fuel properties}

For commercial applications in the compression-ignition engines, biodiesel should meet ASTM D6751 standard specification. The key properties of biodiesel were analyzed as per standard methods described in ASTM D613 for cetane number, ASTM D93 for closed-cup flash point, ASTM D445 for kinematic viscosity, ASTM D1480 for relative density, ASTM D664 for acid number, ASTM D2500 for cloud point and ASTM D97 for pour point.

\subsection{Statistical experimental design and optimization}

Statistical experimental design was applied to optimize the reaction conditions for maximum FAME production. Here, a statistical method called response surface methodology (RSM) coupled with a 3-factor-3-level central composite design (CCD) was adopted to obtain maximum response by optimizing three independent variables namely temperature $\left({ }^{\circ} \mathrm{C}\right)$, pressure (MPa) and methanol to lipid mass ratio. Table 1 shows the coded and actual values of reaction parameters used in the design of experiments. The selection of pressure, temperature and methanol to lipid mass ratio as reaction parameters to be optimized was based on the fact that these parameters are directly relevant to process economics and safety concerns. The experiments were conducted in random order and after finishing the experiments, a suitable mathematical model was developed for prediction of the response based on experimental factors. A 95\% confidence level was applied for model development and analysis of variance (ANOVA). The analysis of variance was performed using Minitab software (Version 16.2.1) and the response surface plots were obtained using MatLab R2013b software. All experiments were repeated three times and the results are averaged. The central data point $(0,0,0)$ was replicated five times.

\section{Table 1 - 3-factor-3-level experimental design.}

\begin{tabular}{lccc} 
& \multicolumn{3}{c}{ Coded values } \\
\cline { 2 - 4 } & -1 & 0 & 1 \\
\hline Temperature $\left({ }^{\circ} \mathrm{C}\right)$ & 155 & 185 & 215 \\
Pressure $(\mathrm{MPa})$ & 5.5 & 6.0 & 6.5 \\
Methanol to lipid mass ratio & 1 & 5 & 9 \\
\hline
\end{tabular}

\section{Results and discussion}

\subsection{Characteristics of vegetable oil wastewater sludge}

The characteristics of as-received (wet) vegetable oil wastewater sludge are given in Table 2 . The dry and ash-free sludge contains quite significant amounts of lipid fractions $(12.44 \pm 0.87 \%)$ include triglycerides, diglycerides, monoglycerides, sterols, phospholipids and free fatty acids. The fatty acids in the sludge based on gas chromatography analysis consist of myristic acid (C14:0, 5.7\%), palmitic acid (C16:0, $31.6 \%$ ), palmitoleic acid (C16:1, 24.8\%), stearic acid (C18:0, $10.4 \%)$, oleic acid (C18:1, 16.3\%), linoleic acid (C18:2, 7.4\%), eicosanoic/arachidic acid (C20:0, 2.2\%) and docosanoic/ behenic acid (C22:0, 1.6\%). Similar fatty acid compositions had been reported by Olkiewicz et al. [20] and Mondala et al. [21] for primary and secondary sludges originated from municipal wastewater treatment facilities (Table 3). The distribution of fatty acids is also in good agreement with sludges originated from sunflower oil [24] and palm oil [25] industries, which mainly comprised of C16-C18 fatty acids ( 90\%). High moisture content of the sludge is necessary to conduct in-situ transesterification process where fatty acids are simultaneously extracted and transesterified to fatty esters. Compared to conventional process employing solid or liquid catalysts, water content should be taken into consideration because water can hydrolyze fats to form free fatty acids, which then form soap and consequently decrease biodiesel yield and cause difficulty in product separation (for basecatalyzed transesterification).

\subsection{Process optimization}

RSM is a collection of mathematical and statistical techniques for empirical model building and optimization, which examines the relation between one or more response parameters and a set of experimental input parameters. The design procedure of RSM to locate the optimum value of response (output parameter) from a set of experimental input parameters can be divided into four steps [26]: (i) designing a series of experiments for reliable and adequate measurements of the response of interest, (ii) constructing a mathematical model of the second order response surface with best fittings, (iii) finding the optimal set of experimental

Table 2 - The characteristics of as-received (wet) wastewater sludge.

\begin{tabular}{lc} 
Parameters & Mass fraction, \% \\
\hline Water content $^{\mathrm{a}}$ & $85.51 \pm 2.38$ \\
Dry matters $^{\text {Lipidic fractions }}{ }^{\mathrm{a}}$ (dry basis) & $14.49 \pm 2.38$ \\
Wax and gum & $10.78 \pm 1.22$ \\
Oil components & $62.13 \pm 4.61$ \\
$\quad$ - Fatty acids & $37.87 \pm 2.35$ \\
$\quad$ - Acylglycerols & $82.05 \pm 3.18$ \\
$\quad$ - Unsaponifiable matters & $10.73 \pm 1.64$ \\
\hline
\end{tabular}

a The values represent the averages of the results for three replicate runs. 
Table 3 - Distributions of fatty acids in various industrial wastewater sludges.

\begin{tabular}{|c|c|c|c|c|c|c|c|c|c|c|c|c|c|}
\hline \multirow[t]{2}{*}{ Origin of sludge } & \multirow[t]{2}{*}{ Type of sludge } & \multicolumn{12}{|c|}{ Fatty acids } \\
\hline & & C12:0 & C14:0 & C15:0 & C16:0 & C16:1 & C18:0 & C18:1 & C18:2 & C20:0 & C20:1 & C22:0 & $\mathrm{C} 24: 0$ \\
\hline Municipal & Primary & trace $^{a}$ & $\square$ & trace & $\square$ & $\square$ & $\square$ & $\square$ & $\square$ & - & trace & - & - \\
\hline \multirow[t]{5}{*}{ WWTP $[20,21]$} & & - & $\square$ & - & $\square$ & - & $\square$ & $\square$ & $\square$ & $\mathrm{NR}^{\mathrm{a}}$ & NR & NR & $\square$ \\
\hline & Secondary & $\square$ & $\square$ & - & $\square$ & $\square$ & $\square$ & $\square$ & $\square$ & trace & $\square$ & $\square$ & - \\
\hline & & trace & $\square$ & trace & $\square$ & $\square$ & $\square$ & $\square$ & $\square$ & NR & NR & NR & - \\
\hline & Blended & - & $\square$ & - & $\square$ & $\square$ & $\square$ & $\square$ & $\square$ & NR & NR & NR & $\square$ \\
\hline & Stabilized & - & - & - & $\square$ & $\square$ & $\square$ & $\square$ & $\square$ & NR & NR & NR & - \\
\hline $\begin{array}{l}\text { Pulp \& paper mill } \\
\text { WWTP [22] }\end{array}$ & Blended & - & trace & - & $\square$ & $\square$ & $\square$ & $\square$ & $\square$ & trace & - & - & $\square$ \\
\hline $\begin{array}{l}\text { Swine manure } \\
\text { WWTP [23] }\end{array}$ & Secondary & $\square$ & $\square$ & - & $\square$ & trace & $\square$ & $\square$ & $\square$ & - & - & - & - \\
\hline $\begin{array}{l}\text { Sunflower oil } \\
\text { WWTP [24] }\end{array}$ & Composite & NR & trace & NR & $\square$ & NR & $\square$ & $\square$ & $\square$ & $\square$ & NR & NR & NR \\
\hline $\begin{array}{l}\text { Palm oil } \\
\text { WWTP [25] }\end{array}$ & Secondary & $\square$ & $\square$ & - & $\square$ & trace & $\square$ & $\square$ & $\square$ & trace & - & - & - \\
\hline $\begin{array}{l}\text { Vegetable oil } \\
\text { WWTP (this work) }\end{array}$ & Secondary & - & $\square$ & - & $\square$ & $\square$ & $\square$ & $\square$ & $\square$ & $\square$ & - & $\square$ & - \\
\hline $\begin{array}{l}\text { Fatty acids: C12:0 (l) } \\
\text { C18:1 (oleic acid), C } \\
\text { a Trace (concentra }\end{array}$ & $\begin{array}{l}\text { ic acid), C14:0 ( } \\
2 \text { (linoleic acid } \\
\text { below 1\%), N }\end{array}$ & $\begin{array}{l}\text { istic a } \\
\text { 20:0 (e }\end{array}$ & id), C15 & id), & $\begin{array}{l}\text { anoi } \\
1 \text { (ga }\end{array}$ & id), C1 & $\begin{array}{l}\text { (palm } \\
\text { C22:0 } \\
\text { or zer }\end{array}$ & $\begin{array}{l}\text { acid } \\
\text { henic }\end{array}$ & $\begin{array}{l}\text { 16:1 ( } \\
\text { id), }\end{array}$ & $\begin{array}{l}\text { nitole } \\
\text { (lign }\end{array}$ & $\begin{array}{l}\text { id), } \\
\text { eric ac }\end{array}$ & 0 (ste & acid), \\
\hline
\end{tabular}

parameters that give a maximum or minimum response and (iv) representing direct and interactive effects between input parameters and response as $2 \mathrm{D}$ or $3 \mathrm{D}$ surface or contour plots. It is realized that the energy requirement of in-situ transesterification process under subcritical water and methanol conditions is higher compared to that of acidic- or base-catalyzed transesterification. However, the in-situ technique offers ancillary advantages than the conventional ones since this technique does not require any solid or liquid catalyst to achieve relatively high FAME yield and eliminating the need for pretreatment steps. In order to implement this method for large-scale operation, optimization of reaction condition is important to give maximum benefit from an economic viewpoint. In this light, RSM was applied to obtain the optimum condition for production of fatty esters by integrating temperature, pressure and methanol to lipid mass ratio simultaneously. The designed experiments based on 3-factor-3-level CCD model are presented in Table 4.

The fitting model, as a function of independent variables, was expressed as a quadratic (second-order) polynomial regression form using least squares analysis:

$Y=k_{0}+\sum_{i=1}^{3} k_{i} X_{i}+\sum_{i=1}^{3} \sum_{j=1}^{3} k_{i j} X_{i} X_{j}$

where $\mathrm{Y}$ is the predicted response, $k_{0}, k_{i}, k_{i i}$ and $k_{i j}$ are the regression coefficients for intercept, linear, quadratic and interaction terms, respectively and $X_{i}$ and $X_{j}$ are the coded levels of independent variables. The second term of Eq. (3) represents linear effect of single process variables while the cross-product term represents an interaction effect between two variables $X_{i}$ and $X_{j}$. After developing the response surface plots, the multiple regression coefficients of the model was estimated using the method of least squares at a significance level of 0.05 and the results are listed in Table 5. As shown in Table 5, it is evident that the main linear effects of temperature $(T)$ and pressure $(P)$ are significant factors toward FAME production. Results also suggested that the square interaction of methanol to lipid mass ratio $\left(\mathrm{M}^{2}\right)$ and an interaction effect between temperature and pressure $\left(T^{*} P\right)$ significantly affects FAME yield. The main linear effect of methanol to lipid mass ratio $(M)$, square interaction of pressure $\left(P^{2}\right)$ and temperature $\left(\mathrm{T}^{2}\right)$, interaction effects between pressure and methanol to lipid mass ratio $\left(P^{*} M\right)$ and temperature and methanol to lipid mass ratio $\left(T^{*} M\right)$ are not significant toward the dependent variable $(\mathrm{Y})$ therefore all these terms except the linear term of methanol to lipid mass ratio $(M)$ and quadratic term of temperature $\left(\mathrm{T}^{2}\right)$ could be removed from the model without affecting the accuracy of predictions. The variables $M$ and $\mathrm{T}^{2}$ still preserved in the model because after elimination of the insignificant terms, the $p$-value of linear term $M$ becomes approximately same to the $\alpha$-level (0.05) thus methanol to lipid mass ratio has significance toward FAME yield. Similarly, the $p$-value of quadratic temperature term $\left(\mathrm{T}^{2}\right)$ satisfies $95 \%$ confidence level. By inserting the values of significant regression coefficients into Eq. (3), the following second-order polynomial coded model for prediction of FAME yield is obtained:

$\begin{aligned} \text { Yield }(\%)= & 67.58+9.89(\mathrm{~T})+5.12(\mathrm{P})+1.64(\mathrm{M})+4.41\left(\mathrm{~T}^{2}\right) \\ & -30.87\left(\mathrm{M}^{2}\right)+3.36(\mathrm{~T} \cdot \mathrm{P})\end{aligned}$

The above coded model fits the data very well with coefficient of determination $\left(R^{2}\right)$ of 0.98 . This indicates that $98 \%$ of the variability in the response could be adequately interpreted by the developed second-order polynomial prediction model. Additionally, all linear, quadratic and interaction terms in the model are significant at $95 \%$ confidence level (Table 5).

The response surface plots of the interaction effects between two independent variables are represented in Fig. 2a-c. As displayed in Fig. 2a, the positive linear influence for both temperature and pressure indicates that FAME yield increases 
Table 4 - The designed experiments based on 3-factor-3-level central composite design.

\begin{tabular}{|c|c|c|c|c|c|}
\hline \multirow[t]{2}{*}{ Run } & \multicolumn{3}{|c|}{ Input parameters } & \multicolumn{2}{|c|}{ Response (FAME yield, \%) } \\
\hline & $\mathrm{P} / \mathrm{MPa}\left(\mathrm{X}_{1}\right)$ & $\mathrm{T} /{ }^{\circ} \mathrm{C}\left(\mathrm{X}_{2}\right)$ & $M\left(X_{3}\right)$ & Experimental $(\mathrm{N}=3)$ & Prediction \\
\hline 1 & $-1(5.5)$ & $1(215)$ & $1(9: 1)$ & $42.35 \pm 2.28$ & 44.17 \\
\hline 2 & $0(6.0)$ & $0(185)$ & $0(5: 1)$ & $67.92 \pm 2.58$ & 67.58 \\
\hline 3 & $1(6.5)$ & $1(215)$ & $-1(1: 1)$ & $58.12 \pm 4.33$ & 57.85 \\
\hline 4 & $-1(5.5)$ & $-1(155)$ & $-1(1: 1)$ & $27.77 \pm 2.02$ & 27.83 \\
\hline 5 & $1(6.5)$ & $-1(155)$ & $1(9: 1)$ & $36.12 \pm 0.89$ & 34.63 \\
\hline 6 & $0(6.0)$ & $0(185)$ & $0(5: 1)$ & $68.15 \pm 1.24$ & 67.58 \\
\hline 7 & $0(6.0)$ & $-1(155)$ & $0(5: 1)$ & $56.33 \pm 3.65$ & 62.10 \\
\hline 8 & $0(6.0)$ & $0(185)$ & $0(5: 1)$ & $67.32 \pm 2.09$ & 67.58 \\
\hline 9 & $1(6.5)$ & $0(185)$ & $0(5: 1)$ & $70.96 \pm 4.12$ & 72.70 \\
\hline 10 & $0(6.0)$ & $0(185)$ & $1(9: 1)$ & $37.12 \pm 2.23$ & 38.35 \\
\hline 11 & $0(6.0)$ & $1(215)$ & $0(5: 1)$ & $84.02 \pm 4.54$ & 81.88 \\
\hline 12 & $0(6.0)$ & $0(185)$ & $-1(1: 1)$ & $32.67 \pm 1.81$ & 35.07 \\
\hline 13 & $-1(5.5)$ & $0(185)$ & $0(5: 1)$ & $65.77 \pm 2.15$ & 62.46 \\
\hline 14 & $1(6.5)$ & 0 (185) & $1(9: 1)$ & $40.38 \pm 2.57$ & 43.47 \\
\hline 15 & $1(6.5)$ & $-1(155)$ & $-1(1: 1)$ & $34.02 \pm 1.12$ & 31.35 \\
\hline 16 & $0(6.0)$ & $0(185)$ & $0(5: 1)$ & $68.25 \pm 4.68$ & 67.58 \\
\hline 17 & $-1(5.5)$ & $1(215)$ & $-1(1: 1)$ & $40.35 \pm 2.54$ & 40.89 \\
\hline 18 & $1(6.5)$ & $-1(155)$ & $0(5: 1)$ & $58.24 \pm 2.88$ & 63.86 \\
\hline 19 & $1(6.5)$ & $1(215)$ & $1(9: 1)$ & $61.02 \pm 3.63$ & 61.13 \\
\hline 20 & $1(6.5)$ & $1(215)$ & $0(5: 1)$ & $92.67 \pm 3.23$ & 90.37 \\
\hline 21 & $1(6.5)$ & $0(185)$ & $-1(1: 1)$ & $38.49 \pm 3.28$ & 40.19 \\
\hline 22 & $0(6.0)$ & $0(185)$ & $0(5: 1)$ & $67.44 \pm 3.51$ & 67.58 \\
\hline 23 & $-1(5.5)$ & $0(185)$ & $-1(1: 1)$ & $31.21 \pm 1.65$ & 29.95 \\
\hline 24 & $0(6.0)$ & $1(215)$ & $-1(1: 1)$ & $43.72 \pm 3.25$ & 49.37 \\
\hline 25 & $-1(5.5)$ & $-1(155)$ & $1(9: 1)$ & $32.77 \pm 1.53$ & 31.11 \\
\hline 26 & $0(6.0)$ & $1(215)$ & $1(9: 1)$ & $47.11 \pm 1.33$ & 52.65 \\
\hline 27 & $-1(5.5)$ & $1(215)$ & $0(5: 1)$ & $83.11 \pm 1.92$ & 73.40 \\
\hline 28 & $0(6.0)$ & $-1(155)$ & $-1(1: 1)$ & $30.11 \pm 2.47$ & 29.59 \\
\hline 29 & $-1(5.5)$ & $-1(155)$ & $0(5: 1)$ & $55.15 \pm 3.08$ & 60.34 \\
\hline 30 & $-1(5.5)$ & $0(185)$ & $1(9: 1)$ & $35.21 \pm 2.42$ & 33.23 \\
\hline 31 & $0(6.0)$ & $-1(155)$ & $1(9: 1)$ & $33.21 \pm 1.79$ & 32.87 \\
\hline
\end{tabular}

as the level of both factors increases. It was observed that the curve line of pressure vs. temperature vs. FAME yield rose sharply by changing the levels of one independent variable from lowest $(-1)$ to highest (1) while keeping another independent variable in the highest level. It is expected that the increase in FAME yield would be greater for temperature rather than pressure since the coded coefficient of

Table 5 - Results of significance test on the multiple regression coefficients of the quadratic polynomial model for estimation of the response (coded form).

\begin{tabular}{|c|c|c|c|c|c|}
\hline \multirow[t]{2}{*}{ No } & \multicolumn{3}{|c|}{ Full } & \multicolumn{2}{|c|}{ Partial $^{\mathrm{a}}$} \\
\hline & Term & $p$-Value & Coefficient & $p$-Value & Coefficient \\
\hline 1 & Intercept & 0.00 & 67.78 & 0.00 & 67.58 \\
\hline 2 & $X_{1}$ & 0.00 & 5.12 & 0.00 & 5.12 \\
\hline 3 & $X_{2}$ & 0.00 & 9.89 & 0.00 & 9.89 \\
\hline 4 & $X_{3}$ & 0.09 & 1.65 & 0.05 & 1.65 \\
\hline 5 & $X_{1}^{2}$ & 0.07 & 1.65 & 0.01 & - \\
\hline 6 & $X_{2}^{2}$ & 0.35 & 3.46 & - & 4.41 \\
\hline 7 & $X_{3}^{2}$ & 0.00 & -31.82 & 0.00 & -30.87 \\
\hline 8 & $\mathrm{X}_{1}^{*} \mathrm{X}_{2}$ & 0.01 & 3.36 & 0.00 & 3.36 \\
\hline 9 & $\mathrm{X}_{2}{ }^{*} \mathrm{X}_{3}$ & 0.78 & -0.28 & - & - \\
\hline 10 & $\mathrm{X}_{1}{ }^{*} \mathrm{X}_{3}$ & 0.80 & -0.25 & - & - \\
\hline
\end{tabular}

${ }^{a}$ Partial means the insignificant terms ( $p$-values $>0.05$ ) of the model are eliminated. temperature is higher than that of pressure. This is also evident on the main effect plots, showing a steeper slope for temperature than for pressure (Fig. 3). Response surface plots in Fig. $2 b$ and $c$ shows that FAME yield tends to have a maximum level for interaction effects between temperature and methanol to lipid mass ratio and pressure and methanol to lipid mass ratio. Maximum FAME production was noticed in the middle levels of both factors while further increase in the factor levels resulted in a gradual decrease in yield. A consistent result was verified on the main effect plot of methanol to lipid mass ratio in Fig. 3. It can be seen the contribution of each parameter investigated has significant effect on FAME yield in the order of temperature $>$ pressure $>$ methanol to lipid mass ratio. After constructing variable design, the optimal levels of process variables were determined. The optimal levels of process variables for in-situ transesterification of wet sludge under subcritical water and methanol conditions are temperature of $215^{\circ} \mathrm{C}$, pressure of $6.5 \mathrm{MPa}$ and methanol to lipid mass ratio of 5.12:1. The predicted FAME yield under this condition was $90.37 \%$ with a model desirability of 0.97 . To further assess the reliability of prediction, three replicate experiments were performed under the condition predicted by the model. Results show that FAME yield of $91.63 \pm 1.72 \%$ was obtained; giving an error of at most $3.3 \%$ and evidencing that the model prediction is highly reliable. 


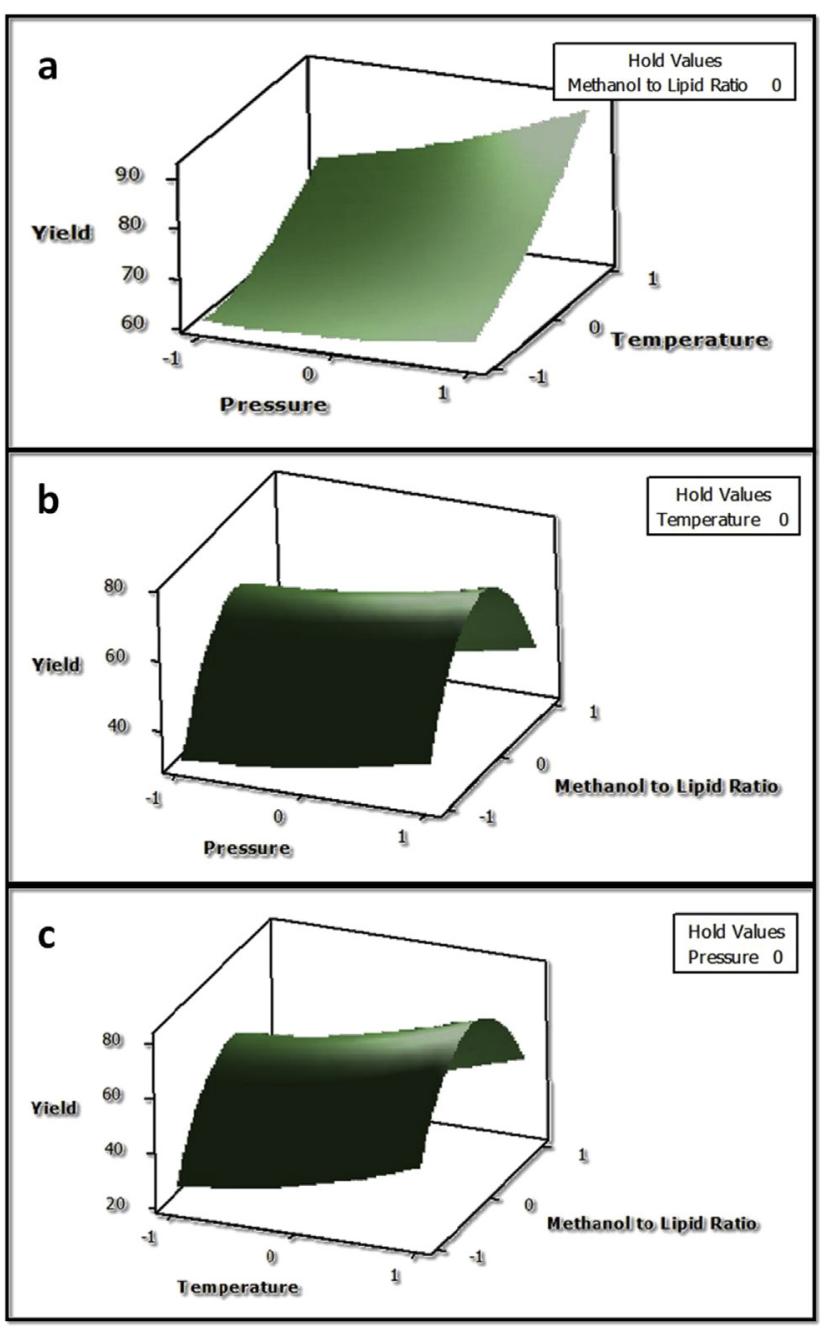

Fig. 2 - 3D response surface plots of FAME yield, showing interaction between pressure and temperature (a), pressure and methanol to lipid mass ratio (b) and temperature and methanol to lipid mass ratio (c).

\subsection{Effect of methanol to lipid mass ratio on FAME yields}

Methanol is the most widely used alcoholic reactant in the production of methyl esters from oils or fats. Stoichiometrically, three moles of methanol are required to produce three moles of methyl esters and one mole of glycerol. Since transesterification is a reversible reaction, excess amounts of methanol are required to shift the reaction to the right-hand side. Excess methanol to lipid molar ratio, to a certain extent, seems favor the equilibrium position moving to the right-hand side. However, the addition of highly excess methanol has a tendency to give negative effects on FAME yields. According to the results obtained, the addition of methanol greater than five times the mass of wet sludge lowers biodiesel yield. A reasonable explanation is that a further increase in methanol amount (9:1), aside from shifting the equilibrium to the right-hand side, would promote the extraction of more polar compounds in the sludge, such as phenols, pigments, carbohydrates and proteins [18], which retards the formation of fatty esters. Excess methanol in the reaction mixture would also interfere with glycerol separation due to increased solubility. Encinar et al. [27] showed there is a slight recombination of fatty esters and glycerol to monoglycerides because their concentration keeps increasing during the course of reaction when an excess alcohol is present. From the equilibrium point of view, excess glycerol concentration could drive the equilibrium back to the left, lowering FAME yields. In addition, increasing methanol amount above the optimal value not only decreases yield but also raises cost for excess reactant recovery.

\subsection{Effect of reaction temperature on FAME yields}

Reaction temperature is the major factor influencing neutral lipids extraction from the sludge and transesterification processes. In the extraction of neutral lipids, temperature changes under isobaric condition vary the polarity and thus solvation properties of water. With increasing temperature, the dielectric constant of water drastically decreased due to weakening of hydrogen bonding between water molecules, allowing greater miscibility between lipids and water [28]. This property of water also makes separation between lipid and water very easy when temperature is reduced to room temperature. The presence of water in the reaction system also initiates hydrolysis of triglycerides to form free fatty acids due to triglycerides-water reactive system. As the hydrolysis proceeds, more free fatty acids are formed which increases the solubility of water in the oil-rich phase and thus the reaction rate. The resulting free fatty acids are esterified by methanol to form methyl esters and glycerol, increasing the product yield.

The effect of reaction temperature on FAME yield is depicted in Fig. 4. The results show that increasing reaction temperature causes an increase in FAME yield. At room temperature, methanol and oil do not mix well and poor methanol and oil miscibility means the reaction rate is very slow. From a kinetic viewpoint, an increase in FAME yield was attributed to enhanced reaction rate at higher temperatures as a result of increased solubility of methanol in the oil-rich phase and higher energy state of the molecules to undergo useful collisions. Also, the time for the mass transfer-controlled region is shortened as temperature is increased [29]. The percent of FAME yields ranged between $34.02 \%$ and $92.67 \%$ at temperatures of $155-215{ }^{\circ} \mathrm{C}$. It is well-known that transesterification between triglycerides and methanol is a reversible and high activation energy reaction. Thus, increasing temperature would favor transesterification of triglycerides to diglycerides, diglycerides to monoglycerides and monoglycerides to methyl esters [29]. In addition, the formation of $\mathrm{H}_{3} \mathrm{O}^{+}$and $\mathrm{OH}^{-}$ionic products from dissociation of water molecules increased with increasing temperature and these ionic products could act either as acid or base catalysts to promote hydrolysis and methanolysis reactions. Below the critical point of mixture, both $\mathrm{H}_{3} \mathrm{O}^{+}$and $\mathrm{OH}^{-}$ionic products promote transesterification reaction under the same catalytic mechanisms using Bronsted acids and alkali catalysts [30]. The increase in temperature also causes the polarity of methanol to decrease by the same phenomenon of that water and it leads to increasing amount 


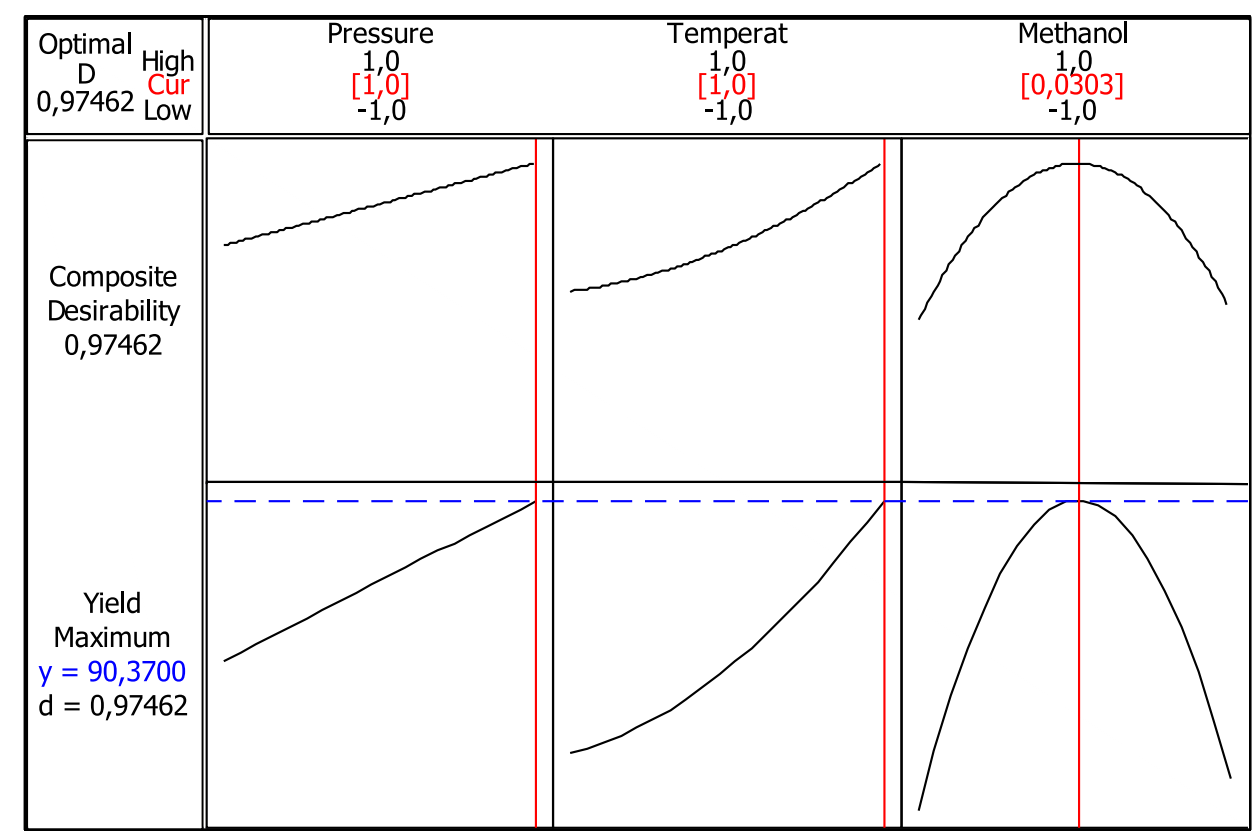

Fig. 3 - Main effect plots of reaction parameters investigated and the response at optimal levels ( $D$ - composite desirability; $\mathrm{y}$ - predicted response; $\mathrm{d}$ - desirability).

of fatty acids that are soluble in the methanol phase. As the system continues to rise in temperature, the initial two-phase oil and methanol mixtures become more homogeneous (single phase) thus facilitates the conversion of triglycerides to fatty esters.

\subsection{Effect of reaction pressure on FAME yields}

Since transesterification and esterification reactions occur in the liquid phase, the pressure inside the reaction vessel should be sufficient to keep methanol and water both in the liquid state at all temperatures. The applied pressures of the in-situ transesterification process under subcritical water and methanol conditions are 5.5, 6.0 and 6.5 MPa. Generally speaking, pressure has only minor effects on the solvent strength of liquid water and methanol. By increasing pressure, the yields of FAME slightly increased as shown in Fig. 4. In the wastewater sludge, the lipids are attached to protein, mineral or carbohydrate structures [18]. When pressure and temperature of the system are increased to subcritical condition, water could enter more easily into the solid matrices where the lipids are trapped in the complex-bonded structures. Chen et al. [31] had also reported similar results in their recent paper for extraction of lipids from wet Nannochloropsis sp. microalgae paste. The ability of subcritical water to extract lipids was due to that the solubility parameter of water becomes closer to the solubility parameter of lipids at elevated pressure and temperature. Also, subcritical water provides enhanced mass-transfer properties of solutes compared to liquid water at room temperature and pressure [15].

In the vicinity of critical point of methanol at $239^{\circ} \mathrm{C}\left(\mathrm{T}_{\mathrm{C}}\right)$ and $8.09 \mathrm{MPa}\left(\mathrm{P}_{\mathrm{C}}\right)$, methanol is highly compressible and the density is a strong function of pressure. The solubility of methanol in the oil-rich phase becomes higher at elevated pressure under critical temperature while only minor amount of oil present in the vapor methanol-rich phase. According to vapor-liquid phase equilibria data reported by Glisic et al. [32], the mole fraction of methanol in the liquid phase at $503 \mathrm{~K}$ and 3.0 MPa was 0.82 and this value increases to 0.98 when pressure is increased to $5.6 \mathrm{MPa}$. Meanwhile, the mole fraction of methanol in the vapor phase remains constant at values close to one, indicating pure methanol in the vapor phase [32]. The higher solubility of methanol in the oil-rich phase with increasing pressure could overcome the interphase masstransfer resistance arising from dissimilarity in size and polarity between lipids and methanol. Thus, this phenomenon can enhance reaction rate of transesterification. The presence of vapor phase in the reaction mixture also contributes on the enhanced chemical kinetics at pressures and temperatures correspond to lower densities of subcritical methanol [32,33]. The highest FAME yield $(92.67 \pm 3.23 \%)$ was obtained at a methanol to lipid mass ratio of 5:1 and under condition in the vicinity of critical point of methanol (6.5 $\mathrm{MPa}$ and $\left.215^{\circ} \mathrm{C}\right)$.

\subsection{Fuel properties of biodiesel}

The fuel properties of biodiesel are varied quite widely, depending upon the quantity and types of fatty acids in the lipid sources and also the refining method. In this regard, the quality of biodiesel produced from wastewater sludge was judged according to ASTM D6751 specification and the results are given in Table 6. Several parameters directly depend upon the fatty ester composition are cetane number, oxidative stability, kinematic viscosity and cold-flow properties in form of the cloud point, pour point and cold filter plugging point (CFPP) [34]. Density is one of the properties of biodiesel that 

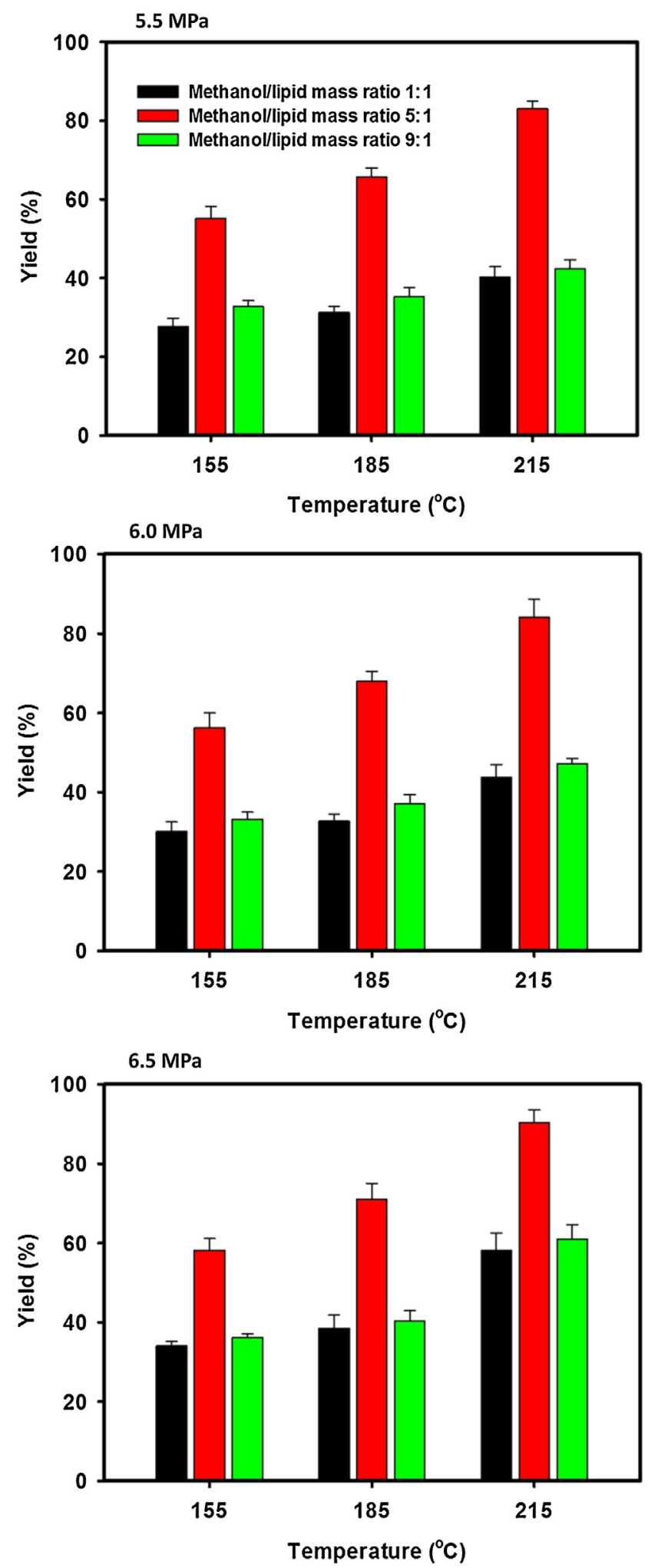

Fig. 4 - Variation of FAME yields with reaction temperatures at different mass ratios of methanol to lipid (1:1, 5:1 and 9:1) and pressures (5.5, 6.0 and 6.5 MPa).

can be used to indicate contamination by unwanted components such as residual alcohol, water and sediment (refers to any substance that is higher in density than biodiesel, such as unreacted monoglycerides and diglycerides). The presence of these contaminants, particularly water could make the fuel becomes rancid, corrode metal parts in fuel lines, accelerate fuel gelling in cold weather and reduce the heat and power of combustion. The density of biodiesel produced in this study is about $885 \mathrm{~kg} \mathrm{~m}^{-3}$. Although the density requirement is not specified in ASTM D6751, the value satisfies EN 14214 standard. Kinematic viscosity is associated with the injection and atomization of the fuel in the combustion chamber of the engine and is also known to impact the engine life and the rate of injector fouling. The sludge-based biodiesel has kinematic viscosity of 2.91-3.17 $\mathrm{mm}^{2} \mathrm{~s}^{-1}$, which is an acceptable viscosity range based on ASTM D6751 standard specification.

The flash point of biodiesel samples is generally over $150{ }^{\circ} \mathrm{C}$, which is much higher than ASTM specification requires. High flash point of biodiesel confirms that this fuel is safer to handle than regular diesel fuel in high temperature environment. Cetane number indicates how well a fuel will combust inside a compression engine and is an important quality parameter for engine performance. Knothe [34] reported that cetane number of biodiesel depends upon the nature of fatty esters comprising the fuel and this combustion-related parameter increases with an increasing fatty acid carbon chain and increasing saturation of components. The cetane number of biodiesel samples in this study exceeds the minimum standard value specified in ASTM D6751, characterizing good ignition and combustion quality. Moreover, high cetane number minimizes soot (carbon) particles and white smoke emissions from the engine during cold start operation. The cetane number obtained in this study agreed well with those of vegetable oils-based biodiesel such as peanut oil methyl ester [35], sunflower oil methyl ester [6], soybean oil methyl ester [3], cottonseed oil methyl ester [6] and rapeseed oil methyl ester [6]. This result may be ascribed to similar distribution of fatty acids in the feedstock from which biodiesel fuel was made.

Acid value is a crucial property for biodiesel quality check due to its relevancy with oxidative stability of the fuel during long-term storage. This parameter is commonly used to indicate free fatty acid content of finished biodiesel. During long-term storage, biodiesel can absorb water which can lead to the formation of free fatty acids from hydrolysis of triglycerides. Biodiesel with an acid value as $\mathrm{KOH}$ higher than $500 \mathrm{mg} \mathrm{kg}^{-1}$ has a greater tendency to corrode fuel tank, linings and pipelines. The vegetable oil sludge methyl esters have acid values as $\mathrm{KOH}$ in the acceptable range of 280-410 $\mathrm{mg} \mathrm{kg}^{-1}$. The cloud point is a measure of lowtemperature operability of the fuel and is well-correlated with filter plugging point. This cold-flow property depends mostly on the fatty acid composition and also the type and quantity of impurities in the fuel. Biodiesel made from saturated fatty acid chains has a higher cloud point compared to biodiesel made from mono- or poly-unsaturated fatty acid chains. From Table 6, it can be seen that vegetable oil sludge methyl esters which mainly comprised of methyl palmitate (29.8\%), methyl palmitoleate (23.4\%) and methyl oleate (15.4\%) have a moderate cloud point about $8{ }^{\circ} \mathrm{C}$. The pour point, a temperature at which the fuel contains many agglomerated crystals and will no longer flow was about $7{ }^{\circ} \mathrm{C}$. The cloud point and pour point of biodiesel can be further lowered by a winterization technique [36], using a branched-chain alcohol 
Table 6 - Fuel properties of biodiesel produced from vegetable oil wastewater sludge. (D - density; KV - kinematic viscosity; FP - flash point; PP - pour point; CP - cloud point; $\mathbf{C N}$ - cetane number; $\mathbf{A N}$ - acid number).

\begin{tabular}{|c|c|c|c|c|c|c|c|}
\hline Sample $^{a}$ & $\begin{array}{c}\mathrm{D} @ 15^{\circ} \mathrm{C} \\
\left(\mathrm{kg} \mathrm{m} \mathrm{m}^{-3}\right)\end{array}$ & $\begin{array}{c}\mathrm{KV} @ 40{ }^{\circ} \mathrm{C} \\
\left(\mathrm{mm}^{2} \mathrm{~s}^{-1}\right)\end{array}$ & $\begin{array}{c}\mathrm{FP} \\
\left({ }^{\circ} \mathrm{C}\right)\end{array}$ & $\begin{array}{c}\mathrm{PP} \\
\left({ }^{\circ} \mathrm{C}\right) \\
\end{array}$ & $\begin{array}{l}\mathrm{CP} \\
\left({ }^{\circ} \mathrm{C}\right)\end{array}$ & $\mathrm{CN}$ & $\begin{array}{l}\mathrm{AN} \text { as } \mathrm{KOH} \\
\left(\mathrm{mg} \mathrm{kg}^{-1}\right)\end{array}$ \\
\hline $155 / 1 / 5.5$ & 885.7 & 2.97 & 163 & 7.2 & 8.2 & 52.8 & 342.5 \\
\hline $185 / 1 / 5.5$ & 886.4 & 2.96 & 155 & 7.1 & 8.0 & 51.7 & 378.3 \\
\hline $215 / 1 / 5.5$ & 886.2 & 3.04 & 158 & 6.8 & 7.6 & 52.7 & 322.6 \\
\hline $155 / 5 / 5.5$ & 886.2 & 3.08 & 161 & 6.9 & 7.8 & 52.6 & 335.2 \\
\hline $185 / 5 / 5.5$ & 885.9 & 3.02 & 157 & 7.1 & 7.9 & 51.7 & 364.1 \\
\hline $215 / 5 / 5.5$ & 885.9 & 3.06 & 156 & 7.0 & 8.1 & 51.1 & 391.2 \\
\hline $155 / 9 / 5.5$ & 884.9 & 2.94 & 165 & 6.8 & 8.0 & 54.0 & 285.4 \\
\hline $185 / 9 / 5.5$ & 885.0 & 2.92 & 162 & 7.2 & 7.8 & 53.7 & 314.8 \\
\hline $215 / 9 / 5.5$ & 884.9 & 2.91 & 165 & 7.1 & 8.0 & 53.5 & 348.6 \\
\hline $155 / 1 / 6.0$ & 885.9 & 2.98 & 160 & 6.9 & 7.7 & 52.4 & 363.0 \\
\hline $185 / 1 / 6.0$ & 886.4 & 2.97 & 155 & 7.0 & 7.9 & 51.6 & 412.7 \\
\hline $215 / 1 / 6.0$ & 886.1 & 3.02 & 157 & 6.8 & 8.2 & 52.5 & 357.8 \\
\hline $155 / 5 / 6.0$ & 885.8 & 3.07 & 159 & 6.7 & 8.1 & 53.0 & 310.6 \\
\hline $185 / 5 / 6.0$ & 885.7 & 3.02 & 157 & 7.2 & 7.9 & 51.9 & 282.5 \\
\hline $215 / 5 / 6.0$ & 885.9 & 3.07 & 154 & 6.9 & 7.8 & 51.0 & 347.2 \\
\hline $155 / 9 / 6.0$ & 884.9 & 2.97 & 170 & 6.6 & 7.6 & 53.9 & 354.4 \\
\hline $185 / 9 / 6.0$ & 885.1 & 2.99 & 165 & 7.0 & 8.1 & 53.4 & 339.1 \\
\hline $215 / 9 / 6.0$ & 884.8 & 2.93 & 162 & 7.1 & 8.0 & 53.5 & 307.3 \\
\hline $155 / 1 / 6.5$ & 885.9 & 2.98 & 158 & 6.9 & 7.7 & 52.4 & 344.9 \\
\hline $185 / 1 / 6.5$ & 886.5 & 3.03 & 157 & 6.6 & 7.6 & 51.8 & 305.8 \\
\hline $215 / 1 / 6.5$ & 886.1 & 3.02 & 160 & 6.8 & 7.9 & 52.5 & 338.5 \\
\hline $155 / 5 / 6.5$ & 886.3 & 3.17 & 163 & 6.7 & 7.5 & 53.1 & 319.8 \\
\hline $185 / 5 / 6.5$ & 885.7 & 3.02 & 160 & 7.1 & 7.7 & 51.9 & 340.2 \\
\hline $215 / 5 / 6.5$ & 885.9 & 3.10 & 156 & 6.9 & 7.6 & 51.0 & 371.3 \\
\hline $155 / 9 / 6.5$ & 885.1 & 2.95 & 165 & 6.9 & 8.1 & 53.9 & 356.6 \\
\hline $185 / 9 / 6.5$ & 885.2 & 3.00 & 168 & 7.2 & 8.3 & 53.7 & 323.5 \\
\hline $215 / 9 / 6.5$ & 884.9 & 2.96 & 172 & 7.0 & 8.0 & 53.8 & 388.1 \\
\hline ASTM D6751 & na & $1.9-6.0$ & $\min 93$ & report & report & $>47$ & $\max 500$ \\
\hline
\end{tabular}

instead of methanol during transesterification [37], adding polymeric cold-flow improvers [38] or blending with other methyl esters having a lower cloud point or No.1/No.2 diesel fuels [39].

\section{Conclusions}

This study demonstrated the synthesis of biodiesel from low grade vegetable oil wastewater sludge with lipid mass fraction of $12.44 \pm 0.87 \%$ (dry and ash-free basis) by a catalyst-free transesterification method. Effects of temperature and pressure show that increasing these parameters contributed positively on FAME yields. The highest FAME yield of $92.67 \pm 3.23 \%$ was obtained at $215^{\circ} \mathrm{C}, 6.5 \mathrm{MPa}$ and methanol to lipid mass ratio of 5:1. The optimum reaction condition for insitu subcritical methanol transesterification of sludge to fatty esters was $215^{\circ} \mathrm{C}, 6.5 \mathrm{MPa}$ and 5.12:1 of methanol to lipid mass ratio with a predicted FAME yield of $90.37 \%$. The predicted FAME yield was in good agreement with experimental results under the optimum reaction condition.

\section{Acknowledgments}

The authors wish to acknowledge the support from Indonesia Toray Science Foundation through ITSF 2012 Research Grant.
The first and second authors also acknowledge partial support provided by the Directorate of Higher Education (DIKTI) through Student Creativity Research Program 2013.

\section{R E F E R E N C E S}

[1] Haas MJ, Foglia TA. Alternate feed stocks and technologies for biodiesel production. In: Knothe G, Krahl J, Gerpen JV, editors. Biodiesel handbook. Urbana, IL: AOCS Press; 2005. pp. 54-61.

[2] Bo X, Guomin X, Lingfeng C, Ruiping W, Lijing G. Transesterification of palm oil with methanol to biodiesel over a $\mathrm{KF} / \mathrm{Al}_{2} \mathrm{O}_{3}$ heterogeneous base catalyst. Energy Fuels 2007;21(6):3109-12.

[3] Tao G, Hua Z, Gao Z, Chen Y, Wang L, He Q, et al. Synthesis and catalytic activity of mesostructured $\mathrm{KF} / \mathrm{Ca}_{x} \mathrm{Al}_{2} \mathrm{O}_{(x+3)}$ for the transesterification reaction to produce biodiesel. RSC Adv 2012;2(32):12337-45.

[4] Mata TM, Sousa IRBG, Vieira SS, Caetano NS. Biodiesel production from corn oil via enzymatic catalysis with ethanol. Energy Fuels 2012;26(5):3034-41.

[5] Hajek M, Skopal F, Capek L, Cernoch M, Kutalek P. Ethanolysis of rapeseed oil by $\mathrm{KOH}$ as homogeneous and heterogeneous catalyst supported on alumina and $\mathrm{CaO}$. Energy 2012;48(1):392-7.

[6] Rakopoulos CD, Antonopoulos KA, Rakopoulos DC, Hountalas DT, Giakoumis EG. Comparative performance and emissions study of a direct injection diesel engine using 
blends of diesel fuel with vegetable oils or bio-diesels or various origins. Energy Convers Manag 2006:47(18-19):3272-87.

[7] Saydut A, Duz MZ, Kaya C, Kafadar AB, Hamamci C. Transesterified sesame (Sesamum indicum L.) seed oil as a biodiesel fuel. Bioresour Technol 2008;99(14):6656-60.

[8] Sinha S, Agarwal AK, Garg S. Biodiesel development from rice bran oil: transesterification process optimization and fuel characterization. Energy Convers Manag 2008;49(5):1248-57.

[9] Bhatti HN, Hanif MA, Qasim M, Ata-ur-Rehman. Biodiesel production from waste tallow. Fuel 2008;87(13-14):2961-6.

[10] Shi W, Li J, He B, Yan F, Cui Z, Wu K, et al. Biodiesel production from waste chicken fat with low free fatty acids by an integrated catalytic process of composite membrane and sodium methoxide. Bioresour Technol 2013 July;139:316-22.

[11] Fadhil AB, Dheyab MM, Saleh LA. Conversion of fish oil into biodiesel fuels via acid-base catalyzed transesterification. Energy Sources Part A 2014;36(14):1571-7.

[12] Dias JM, Alvim-Ferraz MCM, Almeida MF. Production of biodiesel from acid waste lard. Bioresour Technol 2009;100(24):6355-61.

[13] Siddiquee MN, Rohani S. Lipid extraction and biodiesel production from municipal sewage sludges: a review. Renew Sustain Energy Rev 2011;15(2):1067-72.

[14] Kwon EE, Kim S, Jeon YJ, Yi H. Biodiesel production from sewage sludge: new paradigm for mining energy from municipal hazardous material. Environ Sci Technol 2012;46(18):10222-8.

[15] Kronholm J, Hartonen K, Riekkola ML. Analytical extractions with water at elevated temperatures and pressures. Trends Anal Chem 2007;26(5):396-412.

[16] Reddy HK, Muppaneni T, Sun Y, Li Y, Ponnusamy S, Patil PD, et al. Subcritical water extraction of lipids from wet algae for biodiesel production. Fuel 2014 October;133:73-81.

[17] Huynh LH, Kasim NS, Ju YH. Extraction and analysis of neutral lipids from activated sludge with and without subcritical water pretreatment. Bioresour Technol 2010;101(22):8891-6.

[18] Huynh LH, Nguyen PLT, Ho QP, Ju YH. Catalyst-free fatty acid methyl ester production from wet activated sludge under subcritical water and methanol condition. Bioresour Technol 2012 November;123:112-6.

[19] Fedosov SN, Brask J, Xu X. Analysis of biodiesel conversion using thin layer chromatography and nonlinear calibration curves. J Chromatogr A 2011;1218(19):2785-92.

[20] Olkiewicz M, Fortuny A, Stuber F, Fabregat A, Font J, Ch Bengoa. Evaluation of different sludges from WWTP as a potential source for biodiesel production. Procedia Eng 2012;42:634-43.

[21] Mondala A, Liang K, Toghiani H, Hernandez R, French T. Biodiesel production by in situ transesterification of municipal primary and secondary sludges. Bioresour Technol 2009;100(3):1203-10.

[22] Upadhyaya KL, Mondala A, Hernandez R, French T, Green M, McFarland L, et al. Biocrude production by activated sludge microbial cultures using pulp and paper wastewaters as fermentation substrate. Environ Technol 2013;34(13-16):2171-8.
[23] Loughrin JH, Szogi AA. Free fatty acids and sterols in swine manure. J Environ Sci Health B 2006;41(1):31-42.

[24] Saatci Y, Arslan EI, Konar V. Removal of total lipids and fatty acids from sunflower oil factory effluent by UASB reactor. Bioresour Technol 2003;87(3):269-72.

[25] Hayyan A, MdZ Alam, Mirghani MES, Kabbashi NA, Hakimi NINM, Siran YM, et al. Reduction of high content of free fatty acid in sludge palm oil via acid catalyst for biodiesel production. Fuel Process Technol 2011;92(5):920-4.

[26] Myers RH, Montgomery DC, Anderson-Cook CM. Response surface methodology: process and product optimization using designed experiments. 3rd ed. John Wiley \& Sons; 2009.

[27] Encinar JM, Gonzalez JF, Rodriguez-Reinares A. Biodiesel from used frying oil: variables affecting the yields and characteristics of the biodiesel. Ind Eng Chem Res 2005;44(15):5491-9.

[28] Peterson AA, Vogel F, Lachance RP, Froling M, Antal Jr MJ, Tester JW. Thermochemical biofuel production in hydrothermal media: a review of sub- and supercritical water technologies. Energy Environ Sci 2008;1(1):32-65.

[29] Noureddini H, Zhu D. Kinetics of transesterification of soybean oil. J Am Chem Oil Soc 1997;74(11):1457-63.

[30] Meher LC, Sagar DV, Naik SN. Technical aspects of biodiesel production by transesterification - a review. Renew Sustain Energy Rev 2006;10(3):248-68.

[31] Chen M, Liu T, Chen X, Chen L, Zhang W, Wang J, et al. Subcritical co-solvents extraction of lipid from wet microalgae pastes of Nannochloropsis sp. Eur J Lipid Sci Technol 2012;114(2):205-12.

[32] Glisic S, Montoya O, Orlovic A, Skala D. Vapor-liquid equilibria of triglycerides-methanol mixtures and their influence on the biodiesel synthesis under supercritical conditions of methanol. J Serb Chem Soc 2007;72(1):13-27.

[33] Bulgarevich DS, Otake K, Sako T, Sugeta T, Takebayashi Y, Kamizawa C, et al. Hydrogen bonding in supercritical methanol studied by infrared spectroscopy. J Chem Phys 2002;116(5):1995-2003.

[34] Knothe G. "Designer" biodiesel: optimizing fatty ester composition to improve fuel properties. Energy Fuels 2008;22(2):1358-64.

[35] Kaya C, Hamamci C, Baysal A, Akba O, Erdogan S, Saydut A. Methyl ester of peanut (Arachis hypogea L.) seed oil as a potential feedstock for biodiesel production. Renew Energy 2009;34(5):1257-60.

[36] Kerschbaum S, Rinke G, Schubert K. Winterization of biodiesel by micro process engineering. Fuel 2008;87(12):2590-7.

[37] Giraldo SY, Rios LA, Suarez N. Comparison of glycerol ketals, glycerol acetates and branched alcohol-derived fatty esters as cold flow improvers for palm biodiesel. Fuel 2013 June;108:709-14.

[38] Wang J, Cao L, Han S. Effect of polymeric cold flow improvers on flow properties of biodiesel from waste cooking oil. Fuel 2014 January;117(Part A):876-81.

[39] Serrano M, Oliveros R, Sanchez M, Moraschini A, Martinez M, Aracil J. Influence of blending vegetable oil methyl esters on biodiesel fuel properties: oxidative stability and cold flow properties. Energy 2014 February;65:109-15. 